\title{
Estimating the Optimum Duration of Road Projects Using Neural Network Model
}

\author{
${ }^{1}$ Atheer Mahmood Al-saadi, ${ }^{2}$ Salah Kh. Zamiem, ${ }^{3}$ Luma Ahmed A. Al-Jumaili, \\ ${ }^{4}$ Munqith JameelJubair, ${ }^{1}$ Heba Abdalla Al- Hashemi \\ ${ }^{1}$ Ministry of Construction and Housing \\ ${ }^{2}$ Uruk University, Collage of Engineering \\ ${ }^{3}$ Al-Iraqia University, Collage of Engineering \\ ${ }^{4}$ Engineering Fields Company, Privet Sector,Iraq
}

\begin{abstract}
The aim of this study to predictedthe duration of road projects in republic of Iraq. Historical data was adopted for (99) projects for interval between 2000 to 2017 from Roads and Bridges Directorate (RBD). Artificial Neural Network (ANN)model used to estimate the duration usingsix variables (length of road, No.of lane, No.of intersection, volume of earth, type of pavement and furniture level). The methodology used in this study included two important parts, the first part, reviewing the literature of the subject (estimating the duration of the road projects), and the second part, used of a program neuframe v.4 to build the models of neural networks to estimate the duration of road project. The results showed strong correlation between actual duration and predict duration by $(\mathbf{9 0 . 6 \% )}$, minimizes testing error (3.2\%) and training error (4.9\%). The MAPE and Average Accuracy Percentage generated by ANN model were found to be(25.73\%) and(74.27\%) respectively. Therefore, it can be concluded that ANNs model show very good agreement with the actual measurements.
\end{abstract}

Keywords - Artificial Neural Network, Actual Duration, Predict Duration, Mean Absolute Present Error, Average Accuracy, Road Project

\section{INTRODUCTION}

The estimation team gives the construction cost a big importance among the others management item (quality and time) [1]. Therefore, this study aims to highlight the process of estimating the duration in field of the project management. Project duration can only be estimated once when resources are available. The objective of efficiency the project management is to bring the project to achievement on schedule and cost. The accuracy of projects schedule depends on the accuracy of those estimations. [2]

The hallmark of the neural network is massive parallelism and high interconnectivity between a large numbers of relatively simple processors. The information in a neural processor is stored in the interconnection pattern rather than at specific spatial locations uniquely defined by a memory address.

Instead of a central processor that acts on few bits of information at a given time, as it is found in standard computers, a neural network recruits its entire force of processors or "neurons" to work on a given problem all at once. In this manner, the devices seemingly mimic the brain, in which a signal fired from one region to another and back[3].

Two major benefits of Artificial Neural Systems (ANS) are storage capacity and classification speed. ANS can store large number of complex patterns; visual scenes, speech templates and robot movements. It can classify new patterns to store patterns quickly. The classification speed is independent of the number of patterns stored. These features promise new fields of applications, such as real-time pattern recognition, sensory processors, real-time fuzzy expert systems, robot control, and others [4].

\section{RESEARCH AIM}

The main objective of this study is to predict the duration of road projects when the information and data are few in the planning stage of road projects, through the following:

1) Diagnosis factors (variables) affecting the estimation of the duration of roads in the construction sector in the Republic of Iraq.

2) Constructing a mathematical model to estimate road conditions using the Perceptron method of intelligent artificial neural networks.

3) To establish the identity and credibility of the mathematical model developed.

4) Find a mathematical equation to calculate the duration of the road.

5) Find the degree of accuracy of the mathematical equation and indicate the amount of correlation between the planning duration and the actual duration of the roads.

6) The research contributes to the development of a set of recommendations that help to raise the efficiency of the estimators in road projects in Iraq 


\section{RESEARCH JUSTIFICATION}

Research justification can be summarized follows:

1) The scarcity of studies and researches related to the field of artificial neural networks in estimating the length of road projects, which makes this study an original addition to the scientific knowledge in the field of project management, as the results of this study may be a strong incentive for conducting original studies in the future.

2) The lack of reliability of methods and techniques used in estimating the length of road projects in the construction sector in Iraq. As a result, there is an urgent need to use sophisticated modern methods and techniques for the purpose of estimating the duration in road projects based on computer models or mathematical equations of high accuracy

\section{RESEARCH LIMITS}

The limits of this study were defined as follows:

1) Spatial boundaries: This study was done through the Roads and Bridges Directorate (RBD) (one of the formations of the Ministry of Construction and Housing) in the Republic of Iraq.

2) Time Limits: The time period for collecting information and data was selected during 2011 and 2012

\section{RESEARCH METHODOLOGY}

The research methodology included five axes as follows:

1) Axis 1: Introduction to the importance of neural networks in the construction sector

2) Axis II: Review of previous studies.

3) Axis III: Determining the factors affecting the estimation of the duration of road projects and the collection of historical data

4) Axis IV: Development of a mathematical model using the technology of neural networks.

5) Axis V: Analysis and discussion of the results.

6) The sixth axis: the findings and recommendations, and the most important references that have been relied upon in this research.

\section{APPLICATION ANN IN ESTIMATION THE DURATION OF CONSTRUCTION PROJECT}

Studies and research on the subject of neural networks and their relation to the management of construction projects in the construction sector in the Republic of Iraq are few. The researcher studied a number of these studies and researches, including the study of([5], [6], [7], [8], [9], and [10]); the researcher finds that the vast majority of this research was concentrated in the subject of estimating of the construction productivity and cost estimating of the construction projects.

The process of estimating depends on personal experience or on historical data from previous projects, and the engineer who makes the estimation was not based on a mathematical equation with high accuracy in the calculation of construction productivity or in calculating the cost or duration or other items.

Iraqi studies and research did not address the issue of calculating the duration of road projects using smart artificial neural networks according to the researcher's knowledge, except for one attempt by the researcher [11], which was the subject of this study on the estimation of the duration of the implementation of the projects of concrete irrigation channels. As for the Arab and foreign studies and researches, the researcher has studied a number of them, especially those that are based on calculating the duration of the construction projects for the different items based on the artificial neural network technology as shown in Table I; those previous studies did not address the development of mathematical equations accurate. Therefore, this research is considered an attempt by the researcher to enter into this type of researches to calculate the duration of road projects with high accuracy based on artificial neural networks, and the importance of this research was considered a complementary series of previous research in the field of application of neural networks in the project management, but the advantage of this research lies in the use of the neural network (Perceptron), in addition to the study of a number of more influential variables, and concludes this research to find a mathematical equation in order to calculated of the duration of road projects 
TABLE I. Characteristics and Advantage of Previous Studies

\begin{tabular}{|c|c|c|c|c|c|c|}
\hline$\stackrel{ }{\Xi}$ & Year & Title & Country & Objective & $\begin{array}{l}\text { Statistical } \\
\text { Program }\end{array}$ & $\begin{array}{c}\text { Method } \\
\text { Use }\end{array}$ \\
\hline 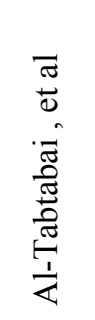 & 1997 & $\begin{array}{l}\text { Expert judgment in } \\
\text { forecasting construction } \\
\text { project completion[12] }\end{array}$ & Kuwait & $\begin{array}{l}\text { This study proposes a } \\
\text { judgment-based } \\
\text { forecasting approach } \\
\text { which will identify } \\
\text { schedule variances } \\
\text { from a baseline plan } \\
\text { for typical } \\
\text { construction projects }\end{array}$ & Non & $\begin{array}{ll}\text { - } & \text { ANN } \\
\text { - } & \text { MLR }\end{array}$ \\
\hline
\end{tabular}

Conclusion: The advantages and limitations of these two modelling process for prediction of schedule variance are discussed. The developed models were integrated with existing project management computer systems for the convenient and realistic generation of revised schedules at appropriate junctures during the progress of the project

\begin{tabular}{|c|c|c|c|c|c|c|}
\hline 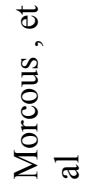 & 2001 & $\begin{array}{l}\text { Preliminary Quantity Estimate } \\
\text { of Highway Bridges Using } \\
\text { Neural Networks[13] }\end{array}$ & Egypt & $\begin{array}{l}\text { Preliminary Quantity } \\
\text { Estimate of Highway } \\
\text { Bridges }\end{array}$ & D.S & ANN \\
\hline
\end{tabular}

Conclusion : These results indicate that artificial neural network are efficient tools for developing preliminaryquantity estimate models that overcome the drawbacks of the current models

\begin{tabular}{|c|c|c|c|c|c|c|}
\hline 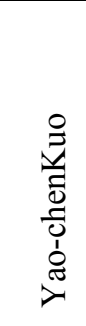 & 2004 & $\begin{array}{l}\text { Highway Earthwork and } \\
\text { Pavement Production Rates } \\
\text { For Construction Time } \\
\text { Estimation [14] }\end{array}$ & Non & $\begin{array}{l}\text { The purpose of this } \\
\text { research study was to } \\
\text { investigate the } \\
\text { production rates of } \\
\text { seven major work } \\
\text { items in earthwork- } \\
\text { and pavement-related } \\
\text { construction }\end{array}$ & SPSS & MLR \\
\hline $\begin{array}{l}\bar{\sigma} \\
\stackrel{0}{0} \\
\Xi \\
\Xi \\
0 \\
0 \\
0 \\
0\end{array}$ & 2009 & $\begin{array}{l}\text { Forecasting Final Budget } \\
\text { and Duration of Highway } \\
\text { Construction Projects[15] }\end{array}$ & \multicolumn{2}{|c|}{\begin{tabular}{|l|l} 
Thailand & $\begin{array}{l}\text { The purpose of this } \\
\text { paper is to develop } \\
\text { models to forecast } \\
\text { final budget and } \\
\text { duration of a } \\
\text { highway } \\
\text { construction project } \\
\text { during construction } \\
\text { stage }\end{array}$ \\
\end{tabular}} & Non & $\begin{array}{l}\text { - } \mathrm{ANN} \\
\text { - } \mathrm{EVM}\end{array}$ \\
\hline \multicolumn{7}{|c|}{$\begin{array}{l}\text { Conclusion: Factors affecting final budget and duration are presented. The forecasting results obtained from } \\
\text { the proposed method based on ANN application are more accurate and stable than those obtained from the } \\
\text { current method based on earned value }\end{array}$} \\
\hline 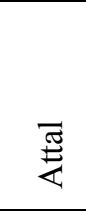 & 2010 & $\begin{array}{l}\text { Development of Neural } \\
\text { Network Models for } \\
\text { Prediction of Highway } \\
\text { Construction Cost and Project } \\
\text { Duration[16] }\end{array}$ & Non & $\begin{array}{l}\text { This research aims to } \\
\text { develop construction cost } \\
\text { and duration prediction } \\
\text { models of highway based } \\
\text { on statistical analysis }\end{array}$ & SPSS & $\begin{array}{l}\text { - } \mathrm{ANN} \\
\text { - } \mathrm{RA}\end{array}$ \\
\hline \multicolumn{7}{|c|}{$\begin{array}{l}\text { Conclusion: This study involved three important points to come up with reliable highway costs and duration } \\
\text { prediction models. The demanded points indicate: finding and sorting of accurate data from projects completed } \\
\text { recently, identification of influential parameters based on the compiled data, and improvement of costs and } \\
\text { construction duration forecasting models. }\end{array}$} \\
\hline
\end{tabular}




\begin{tabular}{|c|c|c|c|c|c|c|}
\hline $\begin{array}{l}0 \\
0 \\
0 \\
0 \\
0 \\
0 \\
0 \\
0 \\
0\end{array}$ & 2012 & $\begin{array}{l}\text { Neural Network Prediction } \\
\text { Model for Construction } \\
\text { Project Duration[17] }\end{array}$ & Bosnia & $\begin{array}{l}\text { Predication the duration } \\
\text { of construction project }\end{array}$ & $\begin{array}{l}\text { Deceptive } \\
\text { Statistical }\end{array}$ & $\begin{array}{ll}\text { - } & \text { MLR } \\
\text { - } & \text { MLP }\end{array}$ \\
\hline
\end{tabular}

Conclusion : The linear regression model for predicting the real time of construction was estimated by $\mathrm{R} 2=0.73341$, and MAPE $=10.355481$ (for the validation data).MLP model for predicting the real time of construction was estimated by: $\mathrm{R} 2=0.96989$, and $\mathrm{MAPE}=2.4984055$ (for the validation data)

\begin{tabular}{|c|c|c|c|c|c|c|}
\hline $\begin{array}{l}\pi \\
\tilde{U} \\
0 \\
0 \\
\frac{v}{0} \\
0\end{array}$ & 2013 & $\begin{array}{l}\text { A Preliminary Estimate of } \\
\text { Time and Cost in Urban Road } \\
\text { Construction Using Neural } \\
\text { Networks [18] }\end{array}$ & Non & $\begin{array}{l}\text { Estimation preliminary } \\
\text { time and cost in road } \\
\text { construction }\end{array}$ & $\begin{array}{l}\text { Deceptive } \\
\text { Statistical }\end{array}$ & ANN \\
\hline
\end{tabular}

Conclusion: Analyses conducted within the research presented in this study confirm that artificial neural networks (ANN) offer the possibility of satisfying all three criteria. That is, ANNs provide satisfactory accuracy for the preliminary estimate of the duration and cost of projects with the minimum engagement of resources to implement the above analysis.

\begin{tabular}{|c|c|c|c|c|c|c|}
\hline 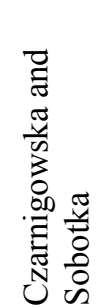 & 2014 & $\begin{array}{l}\text { Estimating Construction } \\
\text { Duration for Public Roads } \\
\text { During the Preplanning } \\
\text { Phase[19] }\end{array}$ & Non & $\begin{array}{l}\text { The aim of the research } \\
\text { was, basing on real-life } \\
\text { cases, to develop a model } \\
\text { of public road building } \\
\text { projects duration }\end{array}$ & 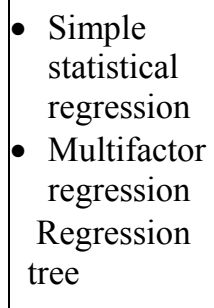 & Non \\
\hline
\end{tabular}

Conclusion : This study investigates into the duration of public road projects and the potential of utilizing data of real-life cases from the past to forecast durations of similar projects in the near future by means of simple regression models

\begin{tabular}{|c|c|c|c|c|c|c|}
\hline 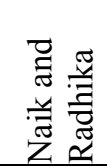 & 2015 & $\begin{array}{l}\text { Time and Cost Analysis for } \\
\text { Highway Road Construction } \\
\text { Project Using Artificial } \\
\text { Neural Networks[20] }\end{array}$ & Non & $\begin{array}{l}\text { Time and cost analysis } \\
\text { for highway road } \\
\text { construction project }\end{array}$ & Non & ANN \\
\hline
\end{tabular}

Conclusion: The application of neural networks when forming a preliminary estimate, would reduce the time and cost of data processing. It helps the contractor to take the decision much easier

\begin{tabular}{|c|c|c|c|c|c|c|}
\hline$\stackrel{\substack{\bar{Z} \\
\Xi}}{\stackrel{\Xi}{\Xi}}$ & 2016 & $\begin{array}{l}\text { Predicting the Duration of } \\
\text { Irrigation Channels Projects in } \\
\text { Iraq by Using ANN } \\
\text { Modelling[11] }\end{array}$ & Iraq & $\begin{array}{l}\text { The aim of this research } \\
\text { is to improve a } \\
\text { mathematical model } \\
\text { using neural network for } \\
\text { predicating the duration } \\
\text { of irrigation channel } \\
\text { project stage }\end{array}$ & SPSS & ANN \\
\hline
\end{tabular}

Conclusion: The validation of the neural network for irrigation channel project in Iraq was very good with the coefficient of determination found to be $(94.2 \%)$, and an average accuracy equal to $93.5 \%$

\begin{tabular}{|c|c|c|c|c|c|c|}
\hline $\begin{array}{l}\pi \\
\tilde{0} \\
\cdot \bar{\Xi} \\
\frac{\pi}{0} \\
\frac{\pi}{\pi}\end{array}$ & 2016 & $\begin{array}{l}\text { Time Prediction Using a } \\
\text { Neuro-Fuzzy Model for } \\
\text { Projects in the Construction } \\
\text { Industry[21] }\end{array}$ & Iran & $\begin{array}{l}\text { This study presents a } \\
\text { prediction model based } \\
\text { on a new neuro-fuzzy } \\
\text { algorithm for estimating } \\
\text { time in construction } \\
\text { projects }\end{array}$ & SPSS & $\begin{array}{l}\text { - fuzzy } \\
\text { sets } \\
\text { theory } \\
\text { (FST) } \\
\text { - ANN }\end{array}$ \\
\hline
\end{tabular}

Conclusion: The construction project is investigated to demonstrate the use and capabilities of the proposed model to see how it allows users and experts to actively interact and, consequently, make use of their own experience and knowledge in the estimation process. The proposed model is also compared to the well-known intelligent model (i.e., BPNN) to illustrate its performance in the construction industry 


\section{FACTORS AFFECTING THE ESTIMATION OF THE DURATION OF ROAD PROJECTS}

The identification and evaluation of the factors that affect the estimation of duration is a critical issue facing the evaluators in order to increase productivity in road projects. Understanding the critical factors that affect the estimation of the duration, whether positive or negative, can contribute to the development of a strategy to reduce the shortcomings and improve the effectiveness of the performance of the construction project. There is an urgent need to identify and understand the various factors that affect the duration of road projects, in order to focus the necessary steps in an effort to reduce the cost of the project and delay the completion of the project, thus increasing the productivity and overall performance of the road project.

Historical data is collected from completed road projects in Iraq from 2000 to 2017. The researcher succeeded in gathering well trusted data for more than 99 projects through visited the Roads and Bridges Directorate (RBD and reading the concerned sheets, documents and reports for road projects. Table II, shows the summary of historical data for road projects. Interviews have been directed to 25 experts in this field. These experts are asked to pinpoint the foremost important factors influencing the duration of road projects, factors affecting the estimation of the duration of road projects were identified as follows:

F1: Duration of road project in (days)

F2: Length of the road in $(\mathrm{km})$

F3: Number of standard lanes in (No.)

F4: Volume of earthworks in (m3)

F5:Number of intersections in (No.)

F6: Types of paving, this classifies pavement as flexible and rigid. And assigns the values of 1 and 2 respectively to them

F7:Road furnishing level, can be divided into two types; normal (1) and high standards (2).

TABLE II. Historical Data for Road Projects

\begin{tabular}{|c|c|c|c|c|c|c|c|}
\hline $\begin{array}{c}\text { Parameter } \\
\text { statistics }\end{array}$ & F1 & F2 & F3 & F4 & F5 & F6 & F7 \\
\hline MAX & 250 & 252 & 4 & 348 & 20 & 2 & 3 \\
\hline MIN & 15 & 3 & 2 & 8 & 1 & 1 & 1 \\
\hline RANGE & 235 & 249 & 2 & 340 & 19 & 1 & 2 \\
\hline AVAREGE & 98.901960 & 66.235294 & 3.5098039 & 107.46078 & 6.3137254 & 1.1176470 & 1.8823529 \\
\hline S.D & 56.3251065 & 52.360657 & 0.8489264 & 88.275386 & 4.4435115 & 0.3158690 & 0.5762781 \\
\hline
\end{tabular}

\section{DEVELOPMENT OF A MATHEMATICAL MODEL USING THE TECHNOLOGY OF} NEURAL NETWORKS

In this study, the researcher used an integrated scientific methodology to build the neural network model to estimate the duration of road projects. This methodology includes the following steps:

1) Selection software

There are much software used in the field of neural networks, including program (Matlab), (GMDH Shell) and (Neurosolutions), but the most common program for researchers is NEUFRAME V.4. This program is easy to use and is far from complicated. NEUFRAMEis an integrated group of Intelligence Technology tools that include Neural Networks logic that allow putting the power of neural nets to work straight out of the boxand the Fig. (1) below illustrates its architectural layout. 


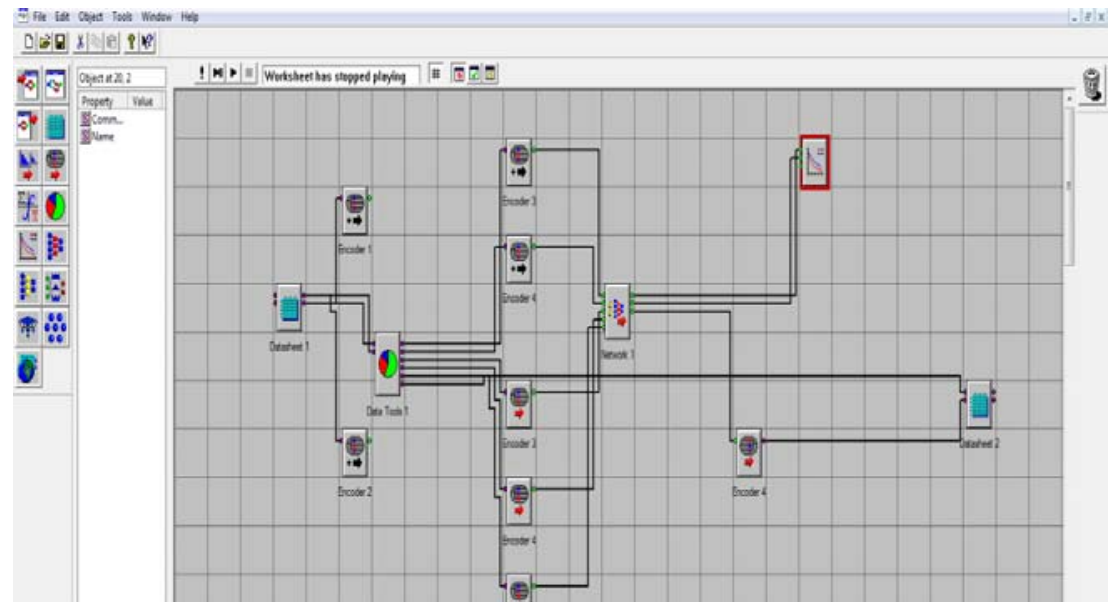

Fig. 1.Architectural of NEUFRAME V.4.

\section{2) Input Actual Data}

The process of selecting the variables in the input and output icon is of great importance that contributes to the improvement of the performance of the neural network. The increase in the number of input and output variables has a significant effect on increasing the size of the neural network, thus reducing the speed of the learning process and thus affecting the efficiency of the neural network.

There are several ways to select the number of variables in the input and output model and the Method of Priori Knowledge was chosen in this case, as this method is widely used in the construction sector and is approved in many researches and studies. This method can be used when there is no prior knowledge of the input variables and their effect on the output variables. Therefore, the input model included the following variables: F2: Length of the road,F3: Number of standard lanes,F4: Volume of earthworks,F5: Number of intersections,F6: Types of paving, F7: Road furnishing level. While the output model included one variablewas F1: Duration of road project. Fig. (2) shows inputs and outputs in the NEUFRAME program.

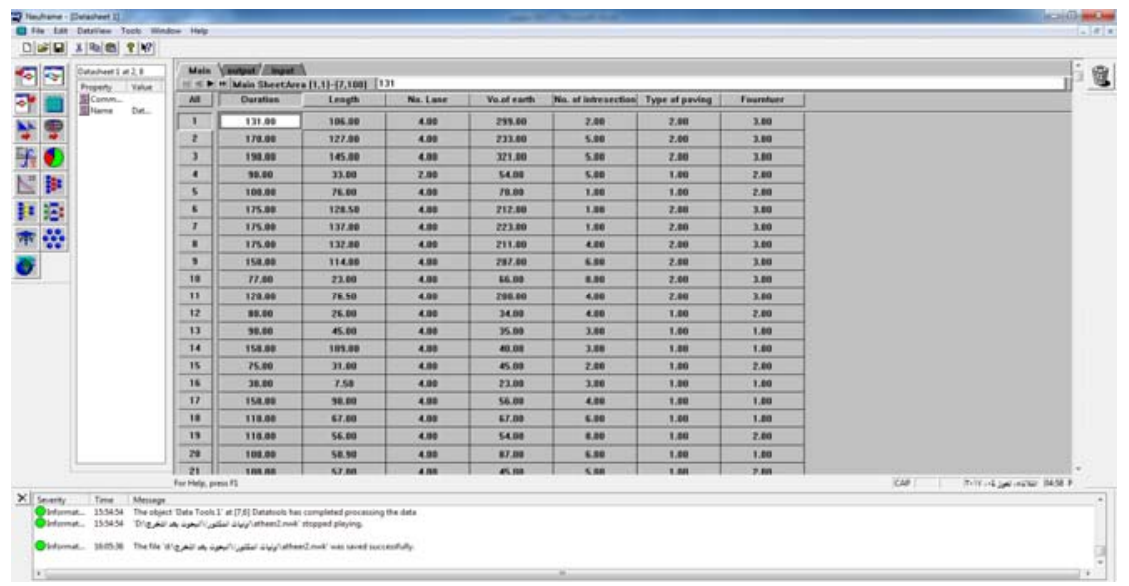

Fig. 2.Inputs and Outputs in the NEUFRAMEProgram

\section{3) Data Division}

Input or output data in the neural network are either continuous variables or discrete variables, and these are divided

The data is divided into three main groups:

1) Training group to build the neural network model (Training Set.)

4) Testing group or testing the neural network model (Testing set.)

4) Validation group to estimate the performance of the model in the applicable environment.

The training group is used to adjust the weights connected to the neural network. Testing group group is used to check the performance of the network at different stages of education, and the training is stopped when the error of the examination group increases. The validation group is used to assess the performance of the model once the neuronal network training has been successfully completed. Therefore, dividing the data into the three groups above is a critical and important step in neural network modeling. 
In this research, the statistical consistency method was used for the purpose of dividing the data into the three groups (the training group, the Testing group and the Validation group). This method ensures statistical suitability of the data for each group, thus ensuring that there is no bias in dividing the data in each group using (T-test) through the use of statistical standards, namely the arithmetic mean and the standard deviation and range. The advantages of this method are that it adopts the trial and error method to reach the best division of data.

Fig. (3) shows the percentage of data breakdown for the training, testing and validation groups using the trial and error method. The researcher used different percentages of data for these groups in an attempt to obtain the best performance of the neural network, namely, reaching the highest correlation coefficient to show the strength of the relationship between the output of the neural network and measured output and in conjunction with the lowest error rate for the testing group, these criteria are adopted in this research to choose the best division of data.

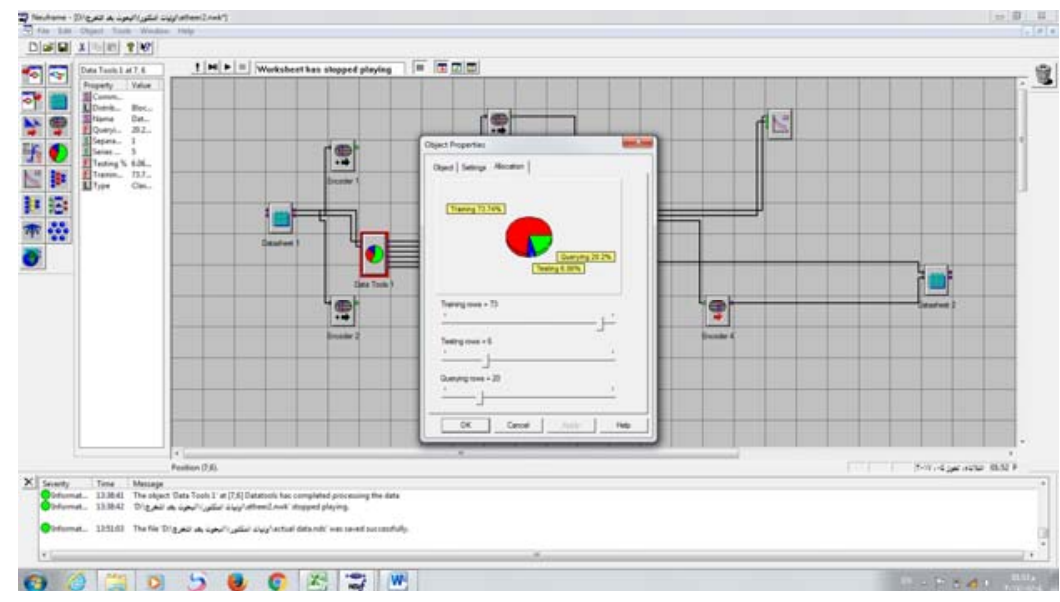

Fig. 3. Percentage of Data Breakdown (Training, Testing, Validation)

Fig. (3) shows that the best division of data is $73.74 \%$ for the training group, $6.06 \%$ for the testing group and $20.2 \%$ for the validation group, with the lowest error rate of the test $(3.2 \%)$ and the largest correlation coefficient (90.6\%), as shown in Fig. (4).

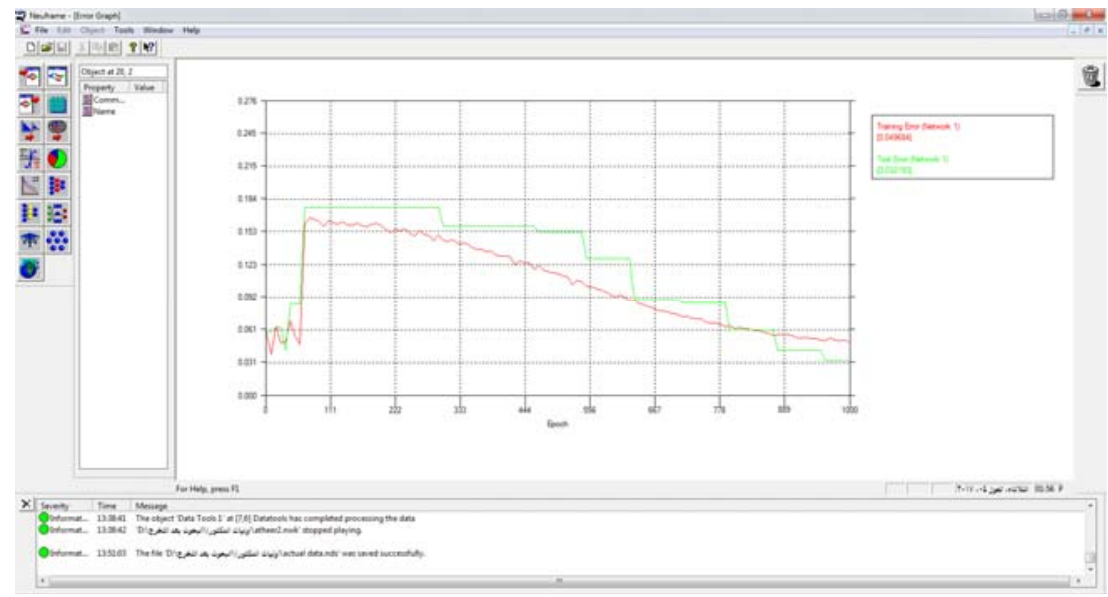

Fig. 4. Training Error and Testing Error

For the purpose of distributing the total data of the 99 variables, the three groups, namely the training group, the testing group and the validation group, the Neuframe program provides an efficient way to distribute the data in three ways:

1) Random mode: In this method, the program randomly distributes variables data on the three groups and according to the percentages obtained in Fig. (3)

2) Strip mode: In this method, the program divides the total data into non-specific sets of packets, and each package includes data for the training group, the testing group and the validation group,

4) Blocked mode: In this mode, the total data is treated as one packet and divided by the three groups. The first $73.4 \%$ of the data is for the training group and $6.06 \%$ for the testing group, and $20.2 \%$ for validation group as shown in Fig. (3) 
In order to study the effect of the use of different options (random, blocked, strip) as shown in Fig. (5), it can be observed that the best performance of the neural network is when using the division method blocked, where it has the least error for the test $(3.2 \%)$.

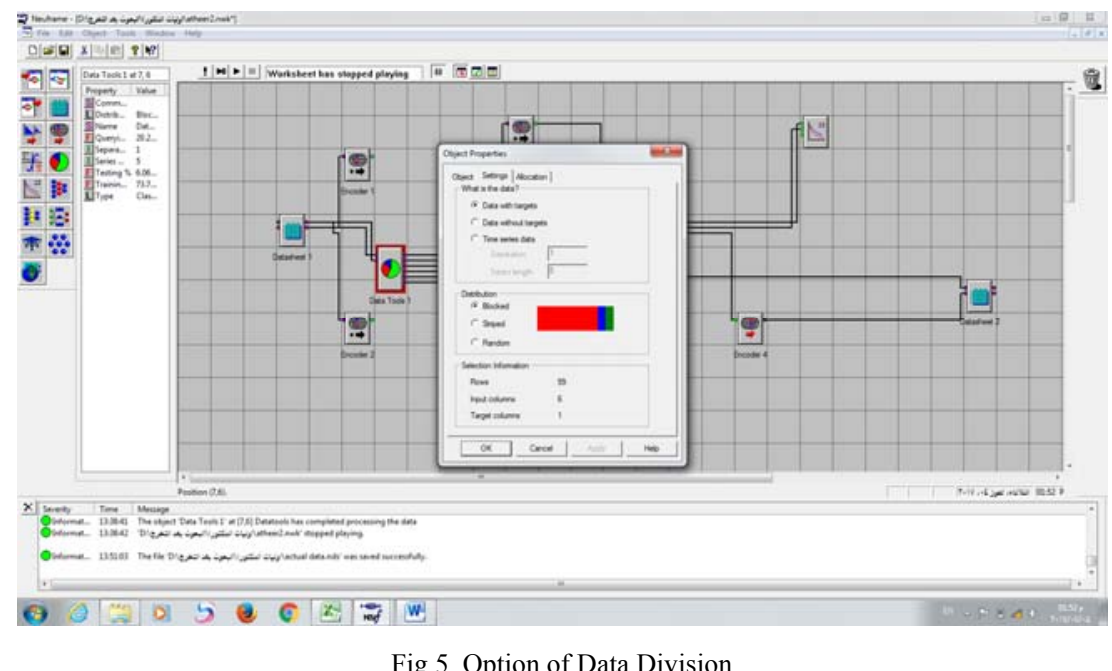

\section{4) Neural Network Architecture}

Artificial neural network architecture is the way neurons connect to each other to form a network. The determination of the appropriate number of neural nodes in the hidden layer of the neural network is an important factor for the success of the neural network, knowing that the number of nodes in the input layer is equal to the number of factors affecting the calculation of duration. Six factors are F2, F3, F4, F5 and F6. The output consists of one neuron can be measured the duration of road project.

Using the default parameters for the program used in this research is the Learning Rate 0.2 and Momentum Term values 0.8 and the Transfer Function in the output layer and the hidden layer is Sigmoid, Thus, the typical form of this network developed in this research is a three-layer neuron is an input layer and includes six neurons and a hidden layer hidden layer comprising three hidden nodes and output layer with only one neuron as shown in Fig. (6) and Fig. (7).

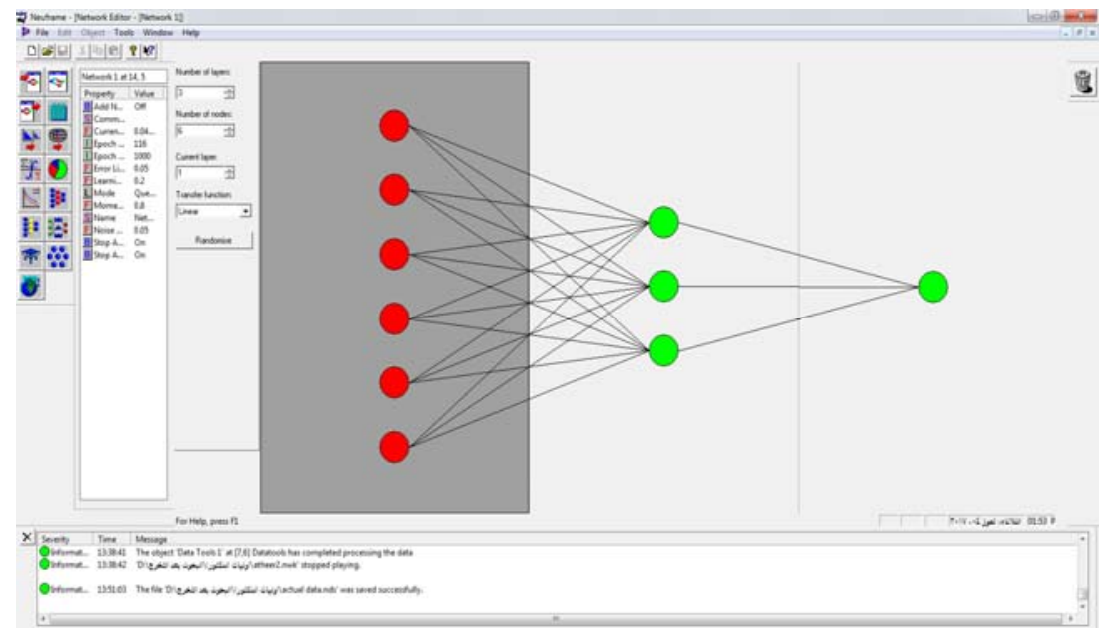

Fig.6. Neural Network Architecture 


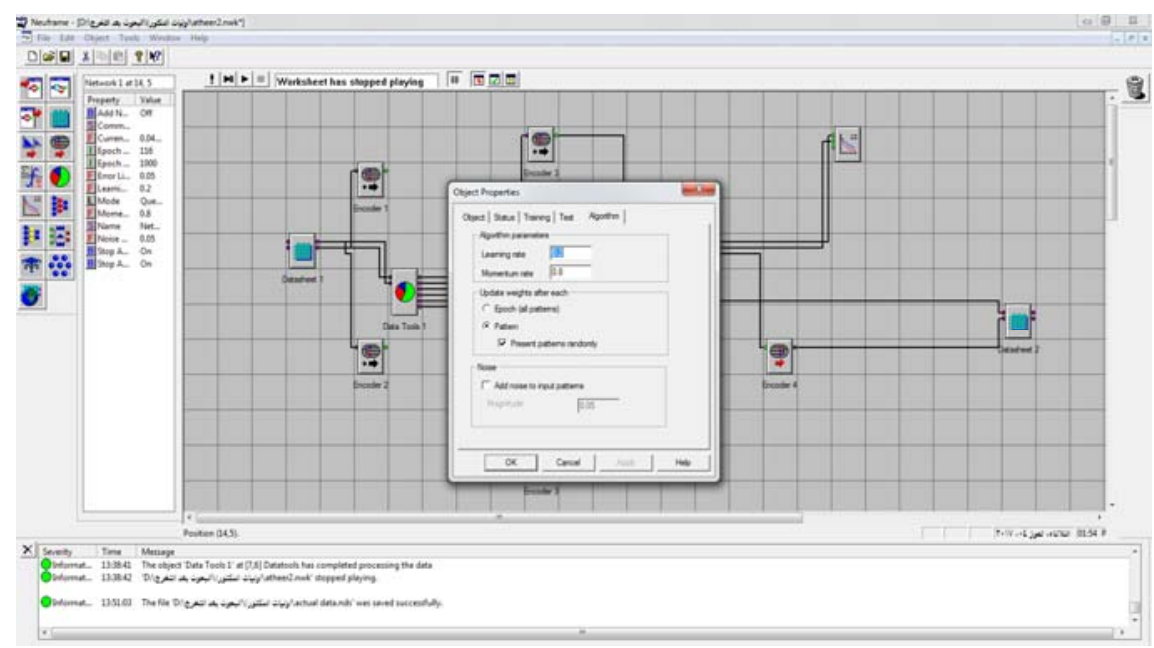

Fig.7. Option of Neural Network Architecture

5) Adjust the weights and extract the mathematical equation

The small number of connection weights obtained by Neuframe for the optimal ANNs model enables the network to be translated into relatively simple formula. To demonstrate this, connection weights and threshold levels (bias) are summarized in Table II.

TABLE III. Detail ofWeights from Node between Input Layer and Hidden Layer

\begin{tabular}{|c|c|c|c|c|c|c|}
\hline \multirow{2}{*}{$\begin{array}{l}\text { Hidden } \\
\text { layer } \\
\text { nodes }\end{array}$} & \multicolumn{5}{|c|}{$w_{j i}($ weight from node $i$ in the input layer to node $j$ in the hidden layer) } & \multirow{2}{*}{$\begin{array}{c}\text { Hidden } \\
\text { layer } \\
\text { threshold } \theta_{\mathbf{j}}\end{array}$} \\
\hline & $\mathrm{i}=1$ & $\mathrm{i}=2$ & $i=3$ & $\mathrm{i}=4$ & $\mathrm{i}=5$ & \\
\hline \multirow{3}{*}{$j=7$} & 1.59391 & 0.33240 & -0.28184 & 0.23627 & 0.02423 & \multirow{3}{*}{0.01399} \\
\hline & $\mathrm{i}=6$ & & & & & \\
\hline & -0.48422 & & & & & \\
\hline \multirow{4}{*}{$\mathrm{j}=8$} & $\mathrm{i}=1$ & $\mathrm{i}=2$ & $i=3$ & $\mathrm{i}=4$ & $i=5$ & \multirow{4}{*}{-0.10511} \\
\hline & -1.87745 & 0.27773 & -0.06430 & 0.12564 & -0.27250 & \\
\hline & $\mathrm{i}=6$ & & & & & \\
\hline & -0.09588 & & & & & \\
\hline \multirow{4}{*}{$\mathrm{J}=9$} & $\mathrm{i}=1$ & $\mathrm{i}=2$ & $i=3$ & $i=4$ & $i=5$ & \multirow{4}{*}{0.64329} \\
\hline & -2.45459 & -0.07094 & -0.3377 & -0.37725 & -0.24731 & \\
\hline & $\mathrm{i}=6$ & & & & & \\
\hline & 0.22411 & & & & & \\
\hline \multirow{2}{*}{$\begin{array}{l}\text { Output } \\
\text { layer } \\
\text { nodes }\end{array}$} & \multicolumn{5}{|c|}{$w_{j i}($ weight from node $i$ in the hidden layer to node $j$ in the output layer) } & \multirow{2}{*}{$\begin{array}{c}\text { Output } \\
\text { layer } \\
\text { threshold } \theta_{\mathrm{j}}\end{array}$} \\
\hline & $\mathrm{i}=7$ & $\mathrm{i}=8$ & $\mathrm{i}=9$ & - & - & \\
\hline $\mathrm{j}=10$ & 2.67135 & -2.44821 & -3.82220 & - & - & 0.39723 \\
\hline
\end{tabular}

Using the connection weights and the threshold levels shown in Table II, the prediction of the equation total cost can be expressed as follows:

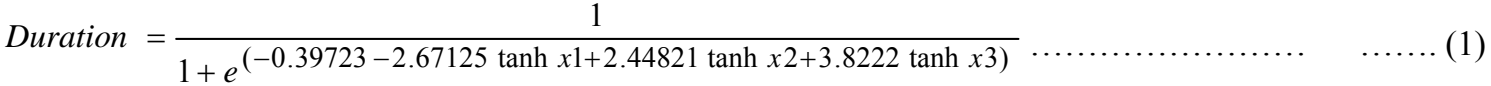

$$
\begin{aligned}
& \mathrm{X} 1=\{07+(w 7-1 * \mathrm{~F} 2)+(w 7-2 * \mathrm{~F} 3)+(w 7-3 * \mathrm{~F} 4)+(w 7-4 * \mathrm{~F} 5)+(w 7-5 * \mathrm{~F} 6)+(w 7- \\
& \left.\left.6^{*} \mathrm{~F} 7\right)\right\} \ldots \ldots \ldots \ldots \ldots \ldots \ldots(2) \\
& \mathrm{X} 2=\{08+(w 8-1 * \mathrm{~F} 2)+(w 8-2 * \mathrm{~F} 3)+(w 8-3 * \mathrm{~F} 4)+(w 8-4 * \mathrm{~F} 5)+(w 8-5 * \mathrm{~F} 6)+(w 8-6 * \mathrm{~F} 7)\} \\
& \mathrm{X} 3=\{99+(w 9-1 * \mathrm{~F} 2)+(w 9-2 * \mathrm{~F} 3)+(w 9-3 * \mathrm{~F} 4)+(w 9-4 * \mathrm{~F} 5)+(w 9-5 * \mathrm{~F} 6)+(w 9-6 * \mathrm{~F} 7)\}
\end{aligned}
$$

It should be noted that, before using Equation 2,3 and 4, all input variables need to be scaled between 0.0 and 1.0. It should also be noted that the predicted value of the duration obtained from Equation 1 is scaled between 0.0 and 1.0 and in order to obtain the actual value this duration has to be re-scaled. The procedure for scaling and substituting the values of the weights and threshold levels from Table II, Equations 1,2,3 and 4 can be rewritten as follows: 
Duration $=\frac{235}{1+e^{(-0.39723-2.67125 \tanh x 1+2.44821 \tanh x 2+3.8222 \tanh x 3)}}+15$

And

$\mathrm{X}_{1}=\{22.11+(0.1 * \mathrm{~F} 2)+(0.2 * \mathrm{~F} 3)+(-0.09 * \mathrm{~F} 4)+(-0.077 * \mathrm{~F} 5)+(0.092 * \mathrm{~F} 6)+(-0.04 * \mathrm{~F} 7)\}$

$\mathrm{X}_{2}=\{41.2+(-0.12 * \mathrm{~F} 2)+(-0.14 * \mathrm{~F} 3)+(-0.025 * \mathrm{~F} 4)+(-0.032 * \mathrm{~F} 5)+(0.02 * \mathrm{~F} 6)+(-0.003 * \mathrm{~F} 7)\}$

$\mathrm{X}_{3}=\{50.90+(-0.14 * \mathrm{~F} 2)+(-0.16 \mathrm{~F} 3)+(-0.15 * \mathrm{~F} 4)+(-0.023 * \mathrm{~F} 5)+(0.01 * \mathrm{~F} 6)+(-0.02 * \mathrm{~F} 7)\}$

6) Validity of the ANN Model

The steps for statistical measuring this model are the same as those used in article [22, 23]. i.e., the statistical measures used to measure the performance of the ANN Model included Mean Percentage Error (MPE), Root Mean Squared Error (RMSE), Mean Absolute Percentage Error (MAPE), Average Accuracy Percentage (AA $\%$ ), The Coefficient of Determination $\left(\mathrm{R}^{2}\right)$ and The Coefficient of Correlation (R); The results of the comparative study are given in Table III, the MAPE and Average Accuracy Percentage generated by ANN model were found to be $25.73 \%$ and $74.27 \%$ respectively. Therefore, it can be concluded that ANNs model show very good agreement with the actual measurements.

TABLE IV. Results of the Realization of the Neural Network Model

\begin{tabular}{|c||c|}
\hline Description & Results \\
\hline \hline MPE & $-14.26 \%$ \\
\hline \hline RMSE & 19.63 \\
\hline MAPE & $25.73 \%$ \\
\hline \hline AA $\%$ & $74.27 \%$ \\
\hline \hline R & $90.6 \%$ \\
\hline \hline $\mathrm{R}^{2}$ & $82.2 \%$ \\
\hline
\end{tabular}

To assess the validity of the ANNs model, the predicted values of Duration are plotted against the measured (observed) values of duration for validation data set, as shown in Fig. (8).

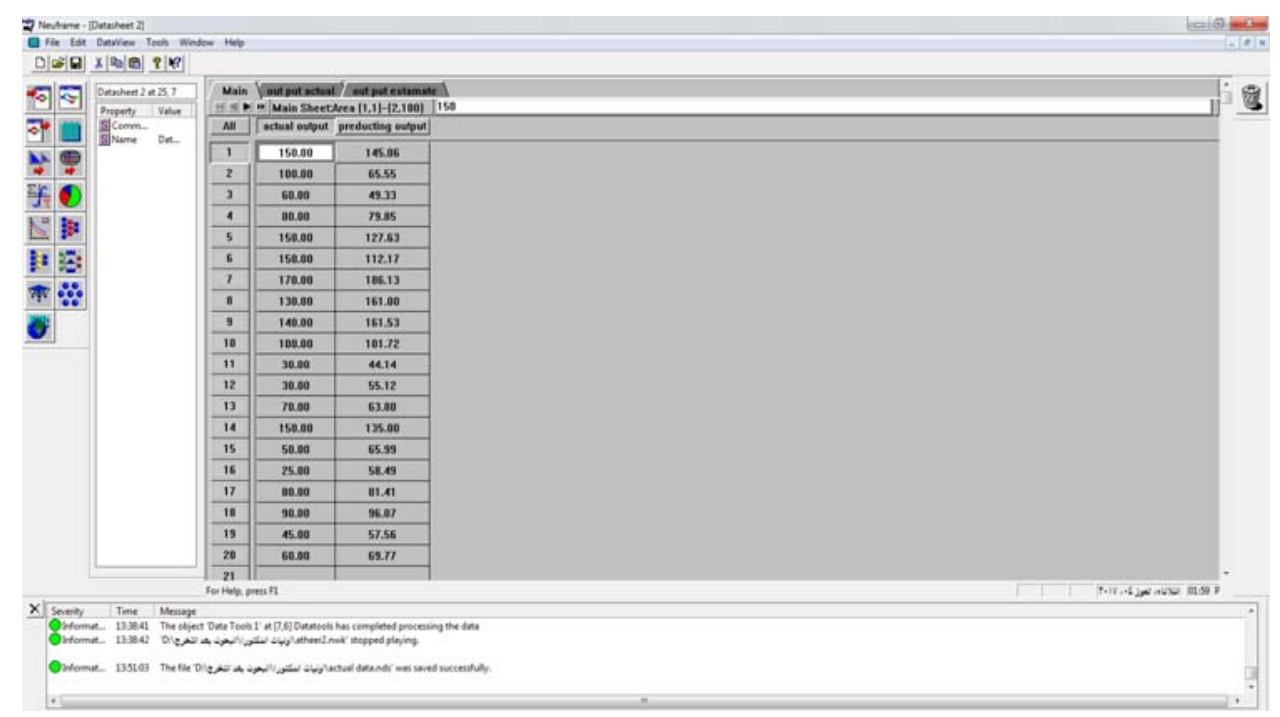

Fig.8. Actual Duration and Predicted Duration

It is clear from Fig. (9). The generalization capability of ANN model uses the validation data set. Coefficient of determination $\left(\mathrm{R}^{2}\right)$ equal to $(82.2 \%)$, therefore it can be concluded that ANNs model show a very good agreement with actual duration. 


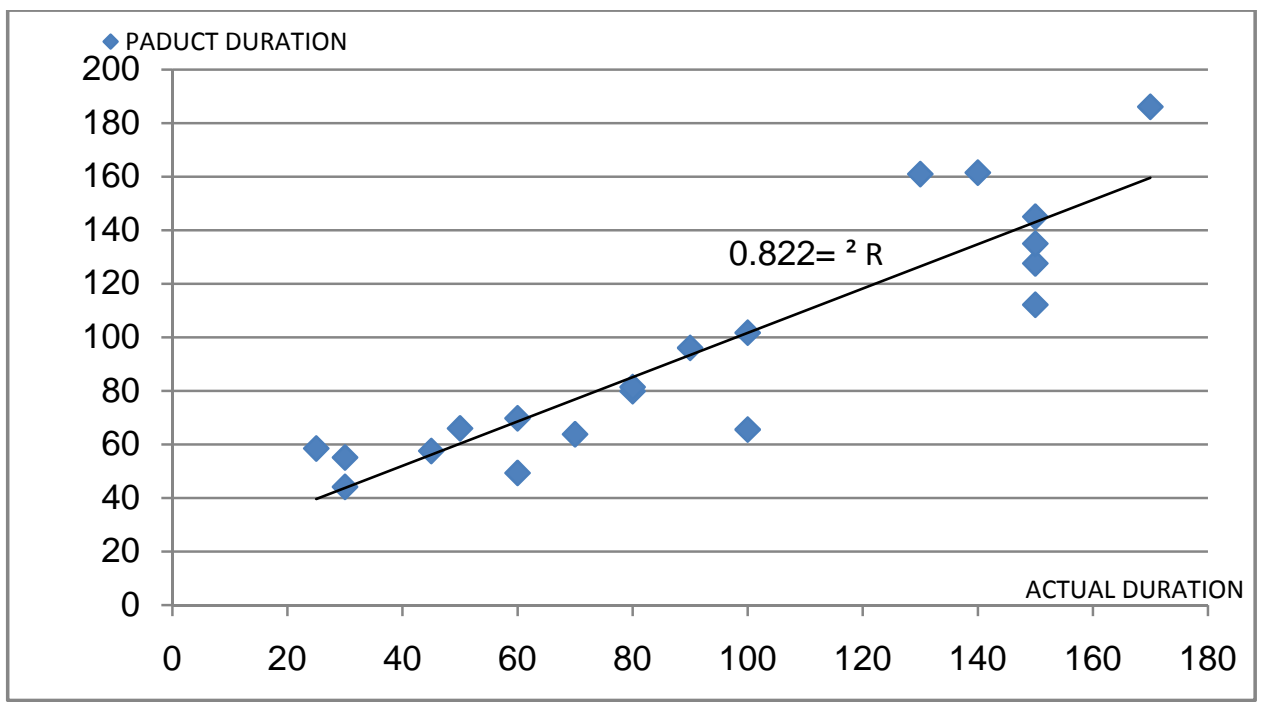

Fig.9. Comparison of Predicted and Observed Duration for Validation Data

\section{CONCLUSION}

The main aim of this study is to use a new approach known as artificial neural networks model to predicting the optimumduration of road projects in field of project management inRepublic of Iraq. The application of artificial neural networks as a new method in the project management was very necessary to ensure the success of project management. One model was built to predict the duration of the road. In this study, multilayered networks were used in the post-error propagation approach. It was found that these networks have an excellent predictability of $74.27 \%$ as average of accuracy and correlation coefficients $(90.6 \%)$.

\section{REFERENCES}

[1] F. M. Al-Zwainy and R. Amer, "Investigation Cost Deviation of Highway Project". Research Journal of Applied Sciences, Engineering and Technology, Vo.13, No.11, PP: 843-855, 2016.

[2] I. A. Mohammed, D. S. Mohsen, F. M. S. Al-Zwainy,Earned Value Management in Construction Project; LAP LAMBERT Academic Publishing, Germany, 2015

[3] Kh. A. Zidan, "High Performance Technique for Face Recognition Based on DCT", Journal of Engineering and Development, Vol. 10, No. 1, March 2006.

[4] Kh. A. Zidan, "Implementation of an Efficient Access Control System for Secure Building", Journal of Engineering and Development, Vol. 12, No. 3, September 2008.

[5] F. M.AL-Zwainy andI. A. Aidan, "Forecasting the Cost of Structure of Infrastructure Projects Utilizing Artificial Neural Network Model (Highway Projects as Case Study)”, Indian Journal of Science and Technology, V.10, No. 20, PP: 1-12 , 2017

[6] F. M. Al-Zwainy, "The use of Artificial Neural Networks for Productivity Estimation of Finishing Stone Works for Building Projects". Journal of Engineering and Development, Vol. 16, No. 2, PP: 42-60, 2012.

[7] F. M. Al-Zwainy."Development of the Mathematical Model for Predicating the Construction Productivity in Iraq Using the Artificial Neural Perceptron Network", Journal of Engineering and Development. Vol.18, No. 2 PP: 1-21, 2014.

[8] F.M. Al-Zwainy, H. A.Rasheed, H. F. Ibrhaneem, "Development of the Construction Productivity Estimation Model Using Artificial Neural Network for Finishing Works for Floors with Marble”. ARPN Journal of Engineering and Applied Sciences, Vol. 7,No.6, PP: $714-22,2012$

[9] R.H. Al-Suhaili, Z. M. Saco and F. M. Al-Zwainy, "Using the Artificial Neural Networks for Predicting the Total Cost of Highway Projects in Iraq", The 2nd Regional Conf. for Eng. Sci. College of Eng.; Iraq. PP:846-867, 2010.

[10] F. M. Al-Zwainy, "The Use of Artificial Neural Network for Estimating Total Cost of Highway Construction Projects" Ph.D. thesis, College of Engineering, Baghdad University, Iraq, 2009.

[11] H. S. M. Al-Jumaily, "Predicting the Duration of Irrigation Channels Projects in Iraq by Using ANN Modelling"Diyala Journal of Engineering Sciences, Vol.9, No.4, PP:62-70, 2016.

[12] H. Al-Tabtabai, N. Kartam, I. Flood and A. Alex "Expert Judgment in Forecasting Construction Project Completion" Engineering Construction and Architectural Management,Vol.4,No.4, PP: 271-293, 1997.

[13] G. Morcous ,M.M.Bakhoum, M. A. Taha and M.El-Said "Preliminary Quantity Estimate of Highway Bridges Using Neural Networks" Proceeding of the Sixth International Conference on the Application of Artificial Intelligence to Civil and Structural Engineering" 2001.

[14] Y. C. Yuo, "Highway Earthwork and Pavement Production Rates for Construction Time Estimation" Ph.D. thesis,University of Texas at Austin, 2004.

[15] W.Pewdum, T.Rujirayanyong and V. Sooksatra, "Forecasting final budget and duration of highway construction projects", Engineering, Construction and Architectural Management, Vol.16, No.6, PP: 544-557, 2009.

[16] A.Attal "Development of Neural Network Models for Prediction of Highway Construction Cost and Project Duration" M.Sc. thesis , Ohio University, Collage of Engineering and Technology , 2010.

[17] S.Petrusiva, V.Zujo and V. Z. Pancovska, "Neural Network Prediction Model for Construction Project Duration"International Journal of Engineering Research and Technology, Vol.1, No.2, 2012.

[18] I.Peško, M.Trivnuic, G.Cirovic, and V.Mucenki“Preliminary Estimate of Time and Cost in Urban Road Constriction Using Neural Networks " Journal of Technical Gazette, Vol.20, No.3, PP:563-570, 2013.

[19] A.Czarnigowska and A. Sobotka"Estimating Construction Duration for Public Road During the Preplanning Phase" Journal of Engineering, Project, and Production Management, Vol.4, No.1, PP:26-35, 2014. 
[20] M. G. Naik and V. Sh. Radhika "Time and Cost Analysis for Highway Road Construction Projects Using Artificial Neural Networks", Journal of Construction Engineering and Project Management, Vol. 4, No.3, PP: 26-30, 2015.

[21] B.Vahdani, S. M. Mousavi, M.Mousakhani and H. Hashemi, "Time Prediction Using a Neuro- Fuzzy Model For Projects in the Construction Industry", Journal of Optimization in Industrial Engineering, Vol. 19, PP:97-103, 2016.

[22] F. M. S. Al-Zwainy, N. T. Hadhal, "Building a Mathematical Model for Predicting the Cost of the Communication Towers Projects Using Multifactor Linear Regression Technique", International Journal of Construction Engineering and Management, Vol. 5, No. 1, PP: 25-29. 2016, doi: 10.5923/j.ijcem.20160501.03.

[23] F.M.S.Al-Zwainy, R.H. Al-Suhaily and Z.M. Saco, Project Management and Artificial Neural Networks: Fundamental and Application. LAP LAMBERT Academic Publishing German. 2015 